This document is confidential and is proprietary to the American Chemical Society and its authors. Do not copy or disclose without written permission. If you have received this item in error, notify the sender and delete all copies.

\title{
Tetramethoxybenzene is a Good Building Block for Molecular Wires: Insights from Photoinduced Electron Transfer
}

\begin{tabular}{|r|l|}
\hline Journal: & The Journal of Physical Chemistry \\
\hline Manuscript ID: & jp-2015-03649h.R1 \\
\hline Manuscript Type: & Article \\
\hline Date Submitted by the Author: & 27-Apr-2015 \\
\hline Complete List of Authors: & $\begin{array}{l}\text { Heinz, Luisa; University of Basel, Department of Chemistry } \\
\text { Yushchenko, Oleksandr; University of Geneva, Dpt. of Physical Chemistry } \\
\text { Neuburger, Markus; University of Basel, Department of Chemistry } \\
\text { Vauthey, Eric; University of Geneva, Dpt. of Physical Chemistry } \\
\text { Wenger, Oliver; University of Basel, Department of Chemistry }\end{array}$ \\
\hline
\end{tabular}

\section{SCHOLARONE ${ }^{\text {IM }}$ \\ Manuscripts}




\title{
Tetramethoxybenzene is a Good Building Block for
}

\section{Molecular Wires: Insights from Photoinduced Electron}

\section{Transfer}

\author{
Luisa G. Heinz,,$^{\dagger}$ Oleksandr Yushchenko, ${ }^{\dagger}$ Markus Neuburger ${ }^{\dagger}$ Eric Vauthey, ${ }^{t^{*}}$ and Oliver S. Wenger ${ }^{\dagger *}$ \\ ${ }^{\dagger}$ Department of Chemistry, University of Basel, St. Johanns-Ring 19, CH-4056 Basel, Switzerland \\ ${ }^{\ddagger}$ Department of Physical Chemistry, University of Geneva, 30 quai Ernest Ansermet, CH-1211 Geneva \\ 4, Switzerland
}

eric.vauthey@unige.ch

oliver.wenger@unibas.ch 


\begin{abstract}
Two donor-bridge-acceptor molecules with terminal triarylamine and $\mathrm{Ru}(\mathrm{bpy})_{3}{ }^{2+}\left(\mathrm{bpy}=2,2^{\prime}-\right.$ bipyridine) redox partners were synthesized and investigated by cyclic voltammetry, optical absorption, luminescence, and transient absorption spectroscopy. The two dyads differ only by the central bridging unit which was tetramethoxybenzene (tmb) in one case and un-substituted phenylene (ph) in the other case. Photo-irradiation of the $\mathrm{Ru}(\mathrm{bpy})_{3}{ }^{2+}$ complex of the two dyads triggers intramolecular electron transfer from the triarylamine to the ${ }^{3}$ MLCT-excited metal complex, and this process occurs with time constants of $1.5 \mathrm{~ns}$ and $6.8 \mathrm{~ns}$ for the tmb- and ph-bridged dyads, respectively. Thermal electron transfer in the reverse direction then leads to disappearance of the photoproduct with a time constant of $10 \mathrm{~ns}$ in both dyads. The faster rate of photoinduced charge transfer in the tmb-bridged dyad can be understood in the framework of a hole tunneling model in which the electron-rich tmb bridge imposes a more shallow barrier than the less electron-rich ph spacer. Until now tmb-based molecular wires have received very little attention, and alkoxy-substituents have been mostly used for improving the solubility of oligo-p-phenylene vinylene (OPV) and oligo- $p$-phenylene ethynylene (OPE) wires. Our study illustrates how four alkoxy-substituents on a phenylene backbone can have a significant influence on the charge transfer properties of a molecular wire, and this is relevant in the greater context of a future molecular electronics technology.
\end{abstract}

\title{
KEYWORDS
}

Electron transfer, transient absorption spectroscopy, photochemistry, molecular electronics, electrochemistry 


\section{INTRODUCTION}

Long-range electron transfer can occur either via tunneling or hopping mechanisms. ${ }^{1-3}$ The latter requires redox-active units in the electron transfer pathway which can temporarily be reduced or oxidized, and such units have sometimes been called "stepping stones". ${ }^{4} 6$ Even though in the tunneling regime the bridge is neither oxidized nor reduced, its electronic structure plays a key role in mediating electronic coupling between the donor and the acceptor. ${ }^{7-12}$ Many researcher have attempted to optimize molecular bridges in order to obtain fast electron or energy transfer over long distances $(>10 \AA)^{10,11,13-}$ ${ }^{36}$ In some of our own recent work we found that electron transfer from a phenothiazine donor to a photogenerated $\mathrm{Ru}(\mathrm{bpy})_{3}{ }^{3+}$ species across a series of four $p$-xylene spacers proceeds with a time constant of $\sim 20 \mu \mathrm{s}$ whereas equidistant charge transfer between the same donor and acceptor across four p-dimethoxybenzene units occurred $\sim 1000$ times faster (Scheme 1). ${ }^{37}$ Dimethoxybenzene is oxidized significantly more easily than xylene, and consequently hole tunneling is associated with a more shallow barrier in the case of $p$-dimethoxybenzene than when $p$-xylene bridging units are present. ${ }^{8,38,39}$ Related observations have been made on various systems by different researchers. ${ }^{38,40-44}$

Scheme 1. Hole transfer from photogenerated $\mathrm{Ru}(\mathrm{bpy}) 3^{3+}$ to phenothiazine across $p$-xylene and $p$ dimethoxybenzene spacers. ${ }^{37}$

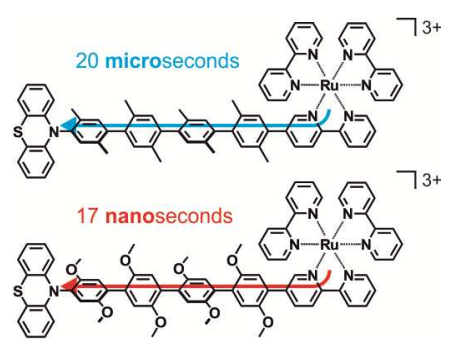

1,2,4,5-Tetramethoxybenzene (tmb) is oxidized even more readily than $p$-dimethoxybenzene, ${ }^{45-47}$ and therefore we reasoned that a molecular bridge containing tmb might be able to mediate long-range 
charge transfer even more efficiently. The electrochemical potential for one-electron oxidation of tmb is in fact so low that the transition from a tunneling to a hopping regime appeared possible in combination with a triarylamine $(\mathrm{TAA}) / \mathrm{Ru}(\mathrm{bpy})_{3}{ }^{2+}$ redox couple. In a prior study we connected tmb directly to a $\mathrm{Ru}(\mathrm{bpy})_{3}{ }^{2+}$ complex and a neighboring $p$-dimethoxybenzene bridge unit. ${ }^{48}$ This molecular design turned out to be sub-optimal because the steric demand of tmb caused large equilibrium torsion angles between tmb and its neighboring building blocks. This is detrimental for long-range electron transfer because $\pi$ conjugation is reduced substantially when increasing the torsion angle between adjacent phenyl or pyridine rings. ${ }^{12,49-51}$ For the present study we therefore flanked the tmb bridging unit with ethynyl groups, resulting in the TAA-tmb-R $\mathbf{u}^{2+}$ dyad shown in Scheme 2. An analogous compound with an un-

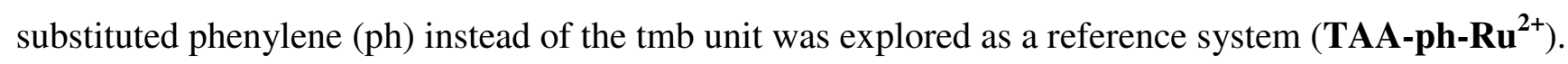

Scheme 2. Molecular structures of the two donor-bridge-acceptor compounds investigated in this work.

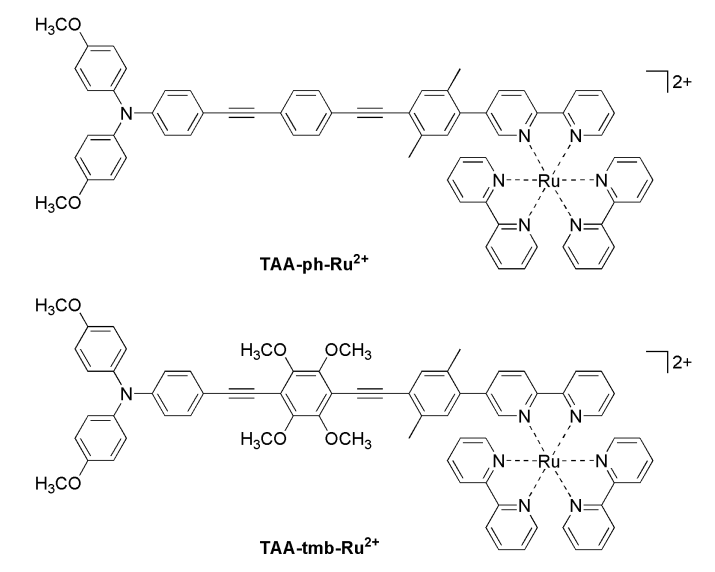

\section{RESULTS AND DISCUSSION}

Synthesis and X-ray crystallography. The two dyads from Scheme 2 each contain a ligand in which a 2,2'-bipyridine (bpy) motif is connected to a triarylamine (TAA) electron donor, either via a tmb or a ph bridging unit. These two ligands (21 and $\mathbf{2 2}$ ) were synthesized as illustrated by Scheme 3 . 
Scheme 3. Synthesis of the ligands with triarylamine donor groups and tmb / ph spacers: (a) $\mathrm{BF}_{3} \cdot \mathrm{Et}_{2} \mathrm{O}$, $\mathrm{MeOH}$; (b) $\mathrm{NaBH}_{4}, \mathrm{EtOH}$; (c) $\mathrm{Me}_{2} \mathrm{SO}_{4}, \mathrm{NaHSO}_{3}, \mathrm{KOH}, \mathrm{EtOH} / \mathrm{H}_{2} \mathrm{O}$; (d) $n$-BuLi, TMEDA, Et $2 \mathrm{O}, \mathrm{I}_{2}$; (e) 2-methyl-3-butyn-2-ol, $\mathrm{PdCl}_{2}\left(\mathrm{PPh}_{3}\right)_{2}, \mathrm{CuI}, \mathrm{Et}_{3} \mathrm{~N}$; (f) NaH, toluene; (g) KOH, toluene; (h) $\mathrm{Pd}_{(}\left(\mathrm{PPh}_{3}\right)_{4}$, THF; (i) $\mathrm{Pd}\left(\mathrm{PPh}_{3}\right)_{4}, \mathrm{Na}_{2} \mathrm{CO}_{3}$, THF / $\mathrm{H}_{2} \mathrm{O}$; (k) ICl, $\mathrm{CH}_{3} \mathrm{CN} / \mathrm{CH}_{2} \mathrm{Cl}_{2}$; (l) $\mathrm{NaO}{ }^{t} \mathrm{Bu}, \mathrm{Pd}(\mathrm{dba})_{2},\left(\mathrm{HP}^{t} \mathrm{Bu}_{3}\right) \mathrm{BF}_{4}$, toluene; (m) $\mathrm{C}_{6} \mathrm{H}_{5} \mathrm{I}\left(\mathrm{CF}_{3} \mathrm{COO}\right)_{2}, \mathrm{I}_{2}, \mathrm{CH}_{2} \mathrm{Cl}_{2} ;$ (n) $\mathrm{PdCl}_{2}\left(\mathrm{PPh}_{3}\right)_{2}, \mathrm{CuI}, \mathrm{Et}_{3} \mathrm{~N}$.

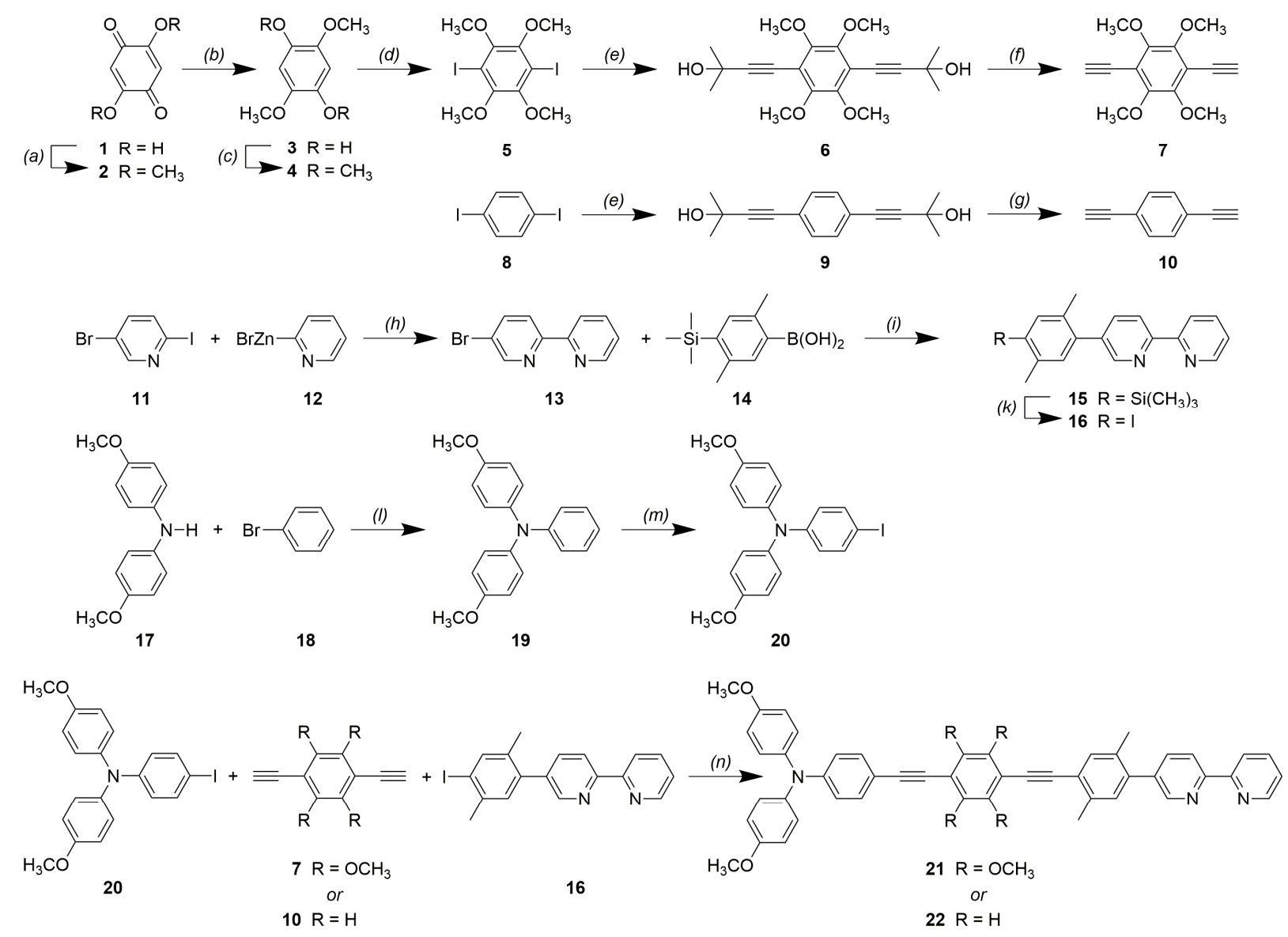

For the TAA-tmb-Ru ${ }^{2+}$ dyad, synthesis started from 2,5-dihydroxy-1,4-benzoquinone (1) which was converted to 1,4-diethynyl-2,3,5,6-tetramethoxybenzene (7) in 6 steps in 53\% overall yield. ${ }^{42,52-54}$ For the TAA-ph- $\mathbf{R u}^{2+}$ dyad, the 1,4-diethynylbenzene (10) building block was available in only 2 steps from commercial 1,4-diiodobenzene (8) in $93 \%$ yield. $^{55}$ The iodoxylene-equipped bpy fragment 16 was accessible in 3 steps from commercial chemicals $(\mathbf{1 1}, \mathbf{1 2}),{ }^{56,57}$ in addition to the two-step synthesis of 4 - 
(trimethylsilyl)phenylboronic acid (14) from 2,5-dibromo- $p$-xylene. ${ }^{58-60}$ The iodo-substituted TAA unit 20 was prepared in 2 steps from bis( $p$-anisyl)amine (17) following a previously published method. ${ }^{61}$ One-pot Sonogashira coupling reactions involving the iodo-substituted TAA donor unit 20, diethynylequipped bridging units $\mathbf{7}$ or 10, and the iodoxylene-equipped bpy fragment $\mathbf{1 6}$ then afforded the desired ligands 21 and 22.

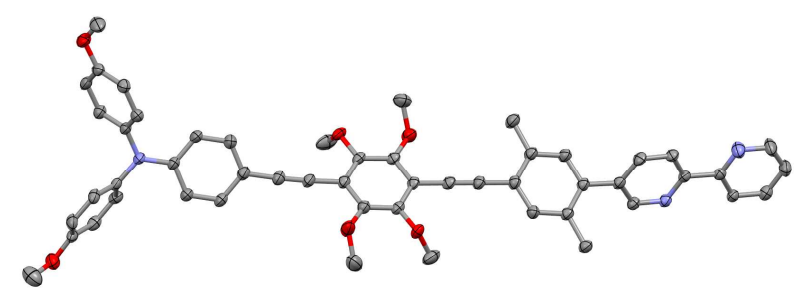

Figure 1. Crystallographic structure of ligand 21 (used for the TAA-tmb-Ru ${ }^{2+}$ dyad). Anisotropic displacement parameters are drawn at the $50 \%$ probability level.

The result of an X-ray diffraction study of single crystals of ligand 21, grown by slow evaporation from acetone solution, is shown in Figure 1. Ligand $\mathbf{2 1}$ crystallizes in space group P-1 with two molecules per unit cell. The triarylamine donor unit adopts its common propeller-shaped structure, ${ }^{62}$ and the bipyridine ligand has its two pyridine units oriented in opposite fashion to each other, as commonly observed. The central tetramethoxybenzene unit is nearly coplanar with the adjacent phenyl rings with torsion angles of $10.1^{\circ}$ and $34.1^{\circ}$ relative to the $p$-xylene unit and the relevant phenyl from the triarylamine, respectively. The distance between the triarylamine $\mathrm{N}$ atom and the center of the bpy ligand is $22.9 \AA$, consequently, the N-Ru (donor-acceptor distance) in the dyad will be roughly $23 \AA$. Ligand 21 arranges in sheets which lie in the crystallographic ab plane.

UV-Vis spectroscopy and electrochemistry. In Figure 2 the optical absorption spectra of TAA-tmb- 
$\mathbf{R} \mathbf{u}^{2+}$ and TAA-ph- $\mathbf{R} \mathbf{u}^{2+}$ in $\mathrm{CH}_{3} \mathrm{CN}$ are shown along with the UV-Vis spectrum of the $\mathrm{Ru}(\mathrm{bpy})_{3}{ }^{2+}$ reference complex measured under identical conditions. In the two dyads, the ${ }^{1}$ MLCT absorption band of the photosensitizer is merely a shoulder to more intense, ligand-centered absorption bands, yet it seems clear that the lowest-energetic electronically excited state is the MLCT state of the Ru(bpy) ${ }_{3}^{2+}$ fragment in both dyads.

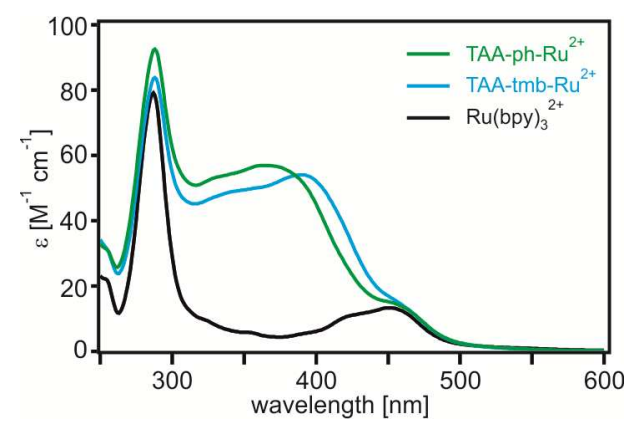

Figure 2. Optical absorption spectra of the two dyads from Scheme 2 along with the UV-Vis spectrum of $\mathrm{Ru}(\mathrm{bpy})_{3}{ }^{2+}$ in $\mathrm{CH}_{3} \mathrm{CN}$.

Cyclic voltammograms obtained using solutions of the two dyads in $\mathrm{CH}_{3} \mathrm{CN}$ in presence of $0.1 \mathrm{M}$ $\mathrm{TBAPF}_{6}$ as a supporting electrolyte are shown in Figure 3. Oxidative and reductive potential sweeps with rates of $0.1 \mathrm{~V} / \mathrm{s}$ were conducted separately because this gave higher quality results. In the reductive sweeps one easily recognizes 3 subsequent reversible waves corresponding to consecutive one-electron reduction of each of the three bpy ligands of the photosensitizer between $-1.8 \mathrm{~V}$ and $-2.2 \mathrm{~V}$ vs. $\mathrm{Fc}^{+} / \mathrm{Fc}$, as commonly detected. ${ }^{63-65}$ In the oxidative sweeps, there is a wave due to triarylamine oxidation around $0.3 \mathrm{~V}$ vs. $\mathrm{Fc}^{+} / \mathrm{Fc}$ and a wave caused by the $\mathrm{Ru}(\mathrm{II}) / \mathrm{Ru}(\mathrm{III})$ couple around $0.8 \mathrm{~V}$ vs. $\mathrm{Fc}^{+} / \mathrm{Fc}$, both in line with expectation. $^{63-66}$ For the isolated 1,2,4,5-tetramethoxybenzene (tmb) molecule an oxidation potential of $0.42 \mathrm{~V}$ vs. $\mathrm{Fc}^{+} / \mathrm{Fc}$ has been reported, ${ }^{45,46}$ but in Figure 3 there is no sign of tmb oxidation, perhaps because its oxidation overlaps with that of the triarylamine. All relevant reduction potentials are summarized in Table 1. 


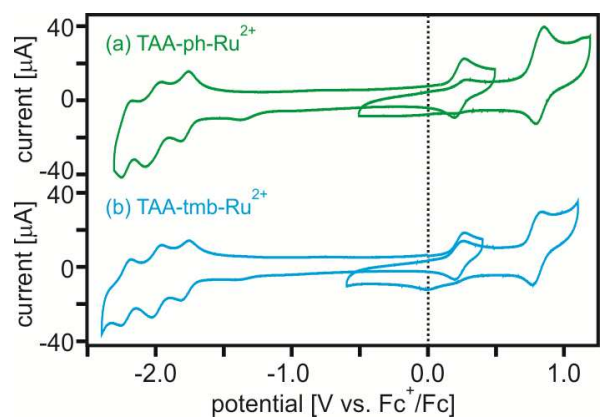

Figure 3. Cyclic voltammograms for the two dyads from Scheme 2 in $\mathrm{CH}_{3} \mathrm{CN}$ with $0.1 \mathrm{M} \mathrm{TBAPF}_{6}$. The potential sweep rates were $0.1 \mathrm{~V} / \mathrm{s}$. The waves at $0.0 \mathrm{~V}$ are due to ferrocene which was added in small quantities for internal potential calibration.

Table 1. Reduction potentials $\left(E^{0}\right)$ for the individual redox-active components of the two dyads from Scheme 2. ${ }^{a}$

\begin{tabular}{|l|c|c|}
\hline & TAA-tmb-Ru & TAA-ph-Ru \\
& ${ }^{2+}$ \\
\hline $\mathrm{Ru}(\mathrm{III}) /(\mathrm{II})$ & 0.80 & 0.81 \\
\hline $\mathrm{TAA}^{+/ 0}$ & 0.23 & 0.23 \\
\hline $\mathrm{tmb}^{+/ 0}$ & $0.42^{b, d}$ & \\
\hline $\mathrm{ph}^{+/ 0}$ & & $2.10^{c, d}$ \\
\hline $\mathrm{bpy}^{0 /-}$ & -1.78 & -1.78 \\
\hline $\mathrm{bpy}^{0 /-}$ & -1.99 & -2.03 \\
\hline $\mathrm{bpy}^{0 /-}$ & -2.21 & -2.22 \\
\hline
\end{tabular}

${ }^{a}$ In $\mathrm{CH}_{3} \mathrm{CN}$ with $0.1 \mathrm{M} \mathrm{TBAPF}_{6}$, measured with potential sweep rates of $0.1 \mathrm{~V} / \mathrm{s}$. All potentials are given in Volts relative to the $\mathrm{Fc}^{+} / \mathrm{Fc}$ couple; ${ }^{b}$ reported in ref. ${ }^{45,46}$ for the 1,2,4,5-tetramethoxybenzene molecule in $\mathrm{CH}_{3} \mathrm{CN}$; ${ }^{c}$ reported in ref. ${ }^{67}$ for the benzene molecule in $\mathrm{CH}_{3} \mathrm{CN}$; ${ }^{d}$ converted from a potential reported in $\mathrm{V}$ vs. $\mathrm{SCE}$ to $\mathrm{V}$ vs. $\mathrm{Fc}^{+} / \mathrm{Fc}$ according to ref. ${ }^{68}$.

Identification of photoproducts. In Figure 4a/d transient absorption spectra obtained after excitation of $2 \cdot 10^{-5} \mathrm{M}$ solutions of the two dyads in aerated $\mathrm{CH}_{3} \mathrm{CN}$ at $532 \mathrm{~nm}$ with laser pulses of $\sim 10 \mathrm{~ns}$ duration 
are shown. The spectra were recorded by averaging over a time period of $200 \mathrm{~ns}$ starting immediately after the excitation pulses. Use of this wavelength leads to selective excitation of the $\mathrm{Ru}(\mathrm{bpy})_{3}{ }^{2+}$

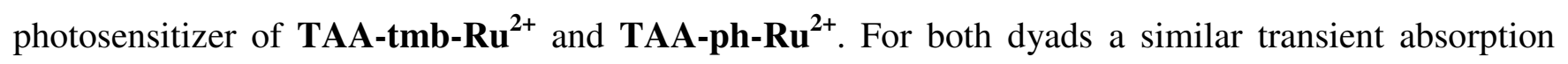
spectrum is obtained: There are absorption bands centered at 740 and $470 \mathrm{~nm}$ in addition to a bleach at

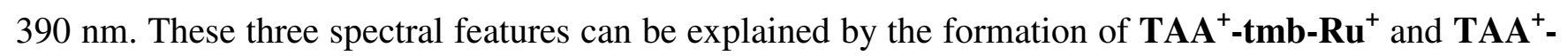
ph- $\mathbf{R u}^{+}$photoproducts as a result of electron transfer from TAA to the photoexcited $\mathrm{Ru}(\mathrm{bpy})_{3}{ }^{2+}$ complex as explained in the following.
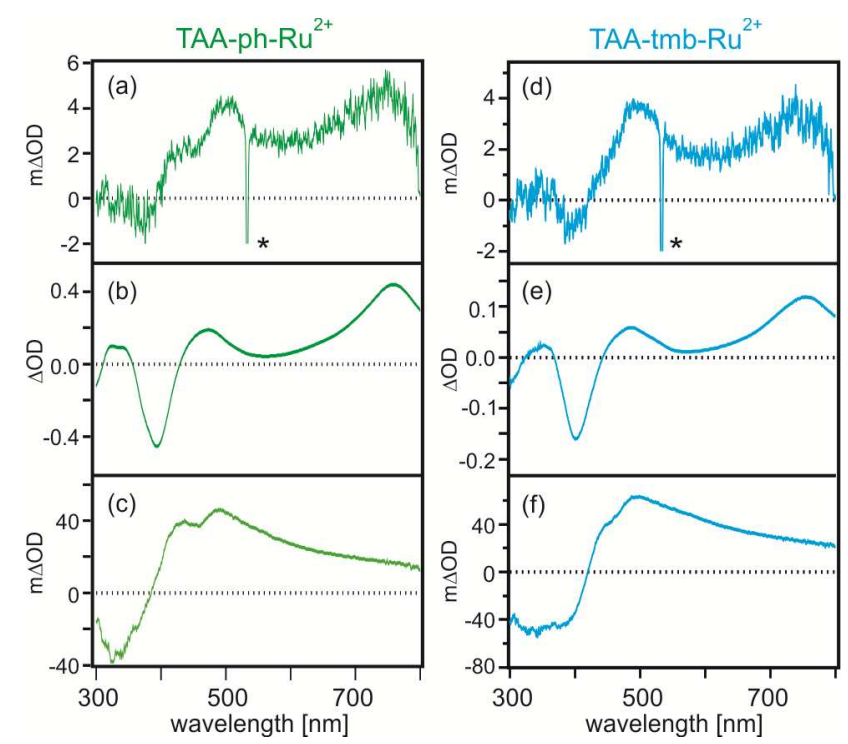

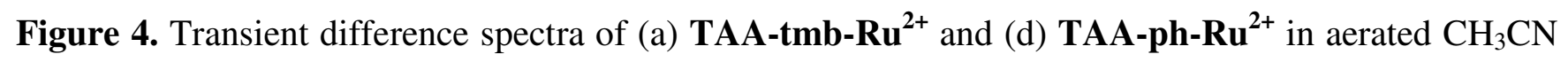
$\left(2 \cdot 10^{-5} \mathrm{M}\right)$ measured after excitation at $532 \mathrm{~nm}$ with laser pulses of $\sim 10 \mathrm{~ns}$ duration. The signal was averaged over a time interval of $200 \mathrm{~ns}$ immediately after excitation. The asterisks (*) mark signals due

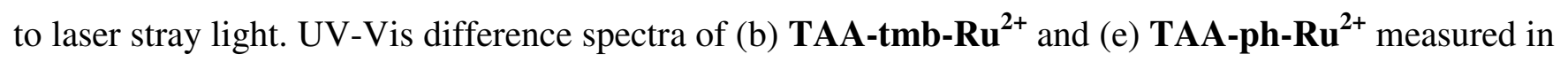
$\mathrm{CH}_{3} \mathrm{CN}$ after addition of one equivalent of $\mathrm{Cu}\left(\mathrm{ClO}_{4}\right)_{2}$ as a chemical oxidant. UV-Vis difference spectra of (c) TAA-tmb- $\mathbf{R u}^{2+}$ and (f) TAA-ph- $\mathbf{R} \mathbf{u}^{2+}$ measured in $\mathrm{CH}_{3} \mathrm{CN}$ after applying a potential of $-1.8 \mathrm{~V}$ vs. $\mathrm{Fc}^{+} / \mathrm{Fc}$ to induce reduction of $\mathrm{Ru}(\mathrm{bpy})_{3}{ }^{2+}$ to $\mathrm{Ru}(\mathrm{bpy})_{3}{ }^{+}$. In $(\mathrm{b}, \mathrm{c}, \mathrm{e}, \mathrm{f})$ the $\mathrm{UV}-\mathrm{Vis}$ spectra recorded before applying any potential served as baselines. 
The UV-Vis difference spectra in Figure 4b/e were measured after addition of one equivalent of $\mathrm{Cu}\left(\mathrm{ClO}_{4}\right)_{2}$ to solutions of $\mathbf{T A A}-\mathbf{t m b}-\mathbf{R} \mathbf{u}^{2+}$ and $\mathbf{T A A}-\mathbf{p h}-\mathbf{R} \mathbf{u}^{2+}$ in $\mathrm{CH}_{3} \mathrm{CN}$ which leads primarily to oxidation of the triarylamine ${ }^{66}$ the spectra obtained before addition of any chemical oxidant served as baselines in both cases. One observes increased absorption at $\sim 750$ and $\sim 475 \mathrm{~nm}$ as well as decreased absorption at $\sim 400 \mathrm{~nm}$ in both dyads. The bands at $\sim 750$ and $\sim 475 \mathrm{~nm}$ are typical for triarylamine radical cations. ${ }^{57,66,69,70}$

The UV-Vis difference spectra in Figure 4c/f were obtained by applying a potential of $-1.8 \mathrm{~V}$ vs. $\mathrm{Fc}^{+} / \mathrm{Fc}$ to solutions of TAA-tmb- $\mathbf{R} \mathbf{u}^{2+}$ and TAA-ph- $\mathbf{R} \mathbf{u}^{2+}$ in $\mathrm{CH}_{3} \mathrm{CN}$ (using a Pt grid electrode); the spectra obtained before applying any potential served as baselines in both cases. At this potential the $\mathrm{Ru}(\mathrm{bpy})_{3}{ }^{2+}$ unit in both dyads can be reduced selectively (Table 1$)$. In both cases this leads to increased absorption above $\sim 400 \mathrm{~nm}$ and to a bleach at shorter wavelengths.

For both dyads the transient absorption spectra (Figure 4a/d) are essentially a 1:1 superposition of the

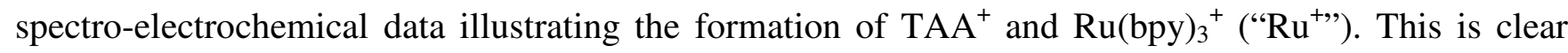
evidence for intramolecular electron transfer from TAA to photoexcited $\mathrm{Ru}(\mathrm{bpy})_{3}{ }^{2+}$ in $\mathbf{T A A - t m b - R \mathbf { u } ^ { 2 + }}$ and TAA-ph- $\mathbf{R} \mathbf{u}^{2+}$. The reaction free energy $\left(\Delta \mathrm{G}_{\mathrm{ET}}{ }^{0}\right)$ for this process can be estimated with the Weller equation (eq. 1), ${ }^{71}$ using the electrochemical potentials from Table 1 and a ${ }^{3}$ MLCT energy ( $\left.E_{00}\right)$ of 2.12 $\mathrm{eV}$ for $\mathrm{Ru}(\mathrm{bpy}) 3^{2+} \cdot{ }^{23,72}$ For a donor-acceptor distance $\left(\mathrm{R}_{\mathrm{DA}}\right)$ of $23 \AA$ (see above), this method yields $\Delta \mathrm{G}_{\mathrm{ET}}{ }^{0}=-0.13 \mathrm{eV}$ for both dyads. The reverse (thermal) electron transfer from $\mathrm{Ru}^{+}$back to TAA ${ }^{+}$to reestablish the starting materials is associated with a reaction free energy $\left(\Delta \mathrm{G}_{\mathrm{bET}}{ }^{0}\right)$ of $-1.99 \mathrm{eV}$ in both dyads. Eq. 2 was employed to estimate the (outer-sphere) reorganization energy $\left(\lambda_{\mathrm{o}}\right)$ associated with photoinduced electron transfer. ${ }^{73,74}$ Using a reactant radius $\left(r_{D}=r_{A}\right)$ of $4.5 \AA$ and the relevant constants for $\mathrm{CH}_{3} \mathrm{CN}\left(\varepsilon_{\mathrm{s}}=35.94, \mathrm{n}=1.3460\right)$ one obtains $\lambda=1.35 \mathrm{eV}$ for both dyads.

$$
\Delta \mathrm{G}_{\mathrm{ET}}{ }^{0}=e \cdot\left(E^{0}\left(\mathrm{TAA}^{+/ 0}\right)-E^{0}\left(\mathrm{bpy}^{0 /-}\right)\right)-\mathrm{E}_{00}-e^{2} /\left(4 \cdot \pi \cdot \varepsilon_{0} \cdot \varepsilon_{\mathrm{s}} \cdot \mathrm{R}_{\mathrm{DA}}\right)
$$




$$
\lambda_{\mathrm{o}}=e^{2} / 4 \cdot \pi \cdot \varepsilon_{0} \cdot\left[\left(2 \cdot \mathrm{r}_{\mathrm{D}}\right)^{-1}+\left(2 \cdot \mathrm{r}_{\mathrm{A}}\right)^{-1}-\mathrm{R}_{\mathrm{DA}}{ }^{-1}\right] \cdot\left(\mathrm{n}^{-2}-\varepsilon_{\mathrm{s}}^{-1}\right)
$$

Assuming that the total reorganization energy $(\lambda)$ is dominated by the outer-sphere contribution $\left(\lambda_{0}\right)$, this analysis then leads to the conclusion that photoinduced electron transfer from TAA to photoexcited $\mathrm{Ru}(\mathrm{bpy})_{3}{ }^{2+}$ takes place in the so-called normal regime in both dyads $\left(-\Delta \mathrm{G}_{\mathrm{ET}}{ }^{0}<\lambda\right)$ whereas the reverse (thermal) electron transfer occurs in the Marcus inverted region $\left(-\Delta \mathrm{G}_{\mathrm{bET}}{ }^{0}>\lambda\right)$. The latter process is in fact closer to the barrierless point, hence one might anticipate more rapid thermal reverse electron transfer than photoinduced (forward) electron transfer.

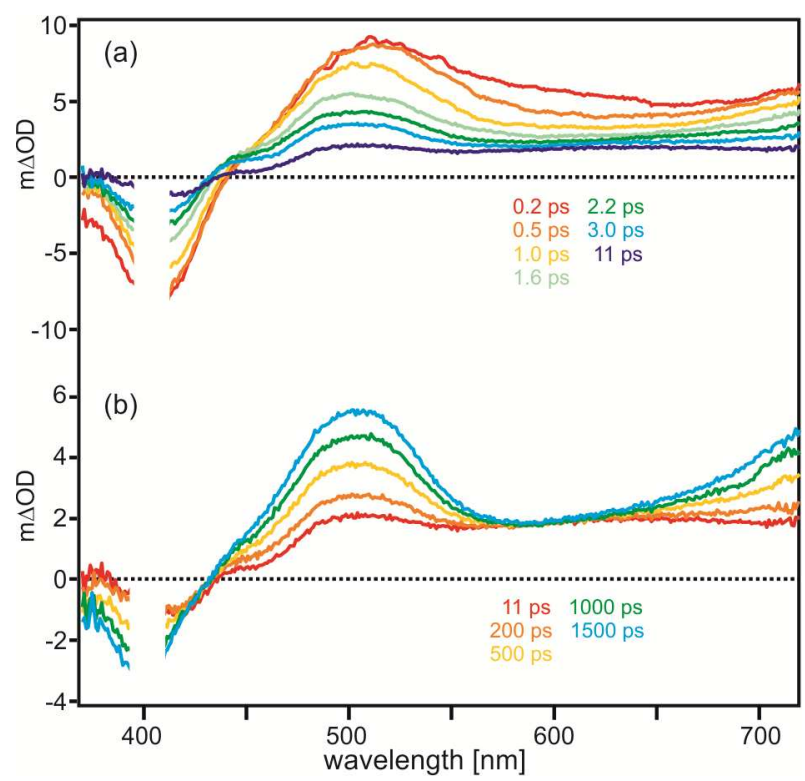

Figure 5. Transient absorption spectra measured at different time delays after excitation of TAA-tmb$\mathbf{R u}^{2+}$ in $\mathrm{CH}_{3} \mathrm{CN}$ at $400 \mathrm{~nm}$ using a fs/ps TA setup. ${ }^{75}$ Analogous data for the TAA-ph- $\mathbf{R} \mathbf{u}^{2+}$ dyad are reported in the Supporting Information (Figure S1).

Kinetics of photoinduced electron transfer. A combination of pico- and nanosecond transient absorption spectroscopy was necessary to explore the electron transfer kinetics in the two dyads from Scheme 2. Following excitation at $400 \mathrm{~nm}$ with a femtosecond laser pulse, ${ }^{75}$ the series of transient 
absorption spectra shown in Figure 5 was obtained for TAA-tmb-Ru' ${ }^{2+}$ in de-aerated $\mathrm{CH}_{3} \mathbf{C N}$. An

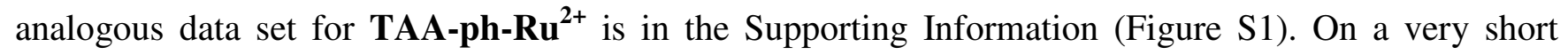
timescale $(<10 \mathrm{ps})$, one observes absorption maxima at 510 and $730 \mathrm{~nm}$ in addition to a bleach near 400 nm. The respective signals decrease over the first 11 ps (Figure 5a) before there is an increase of absorptions with maxima at $500 \mathrm{~nm}$ and above $700 \mathrm{~nm}$, in addition to a growing bleach at $400 \mathrm{~nm}$ (Figure 5b). The temporal evolution of the transient absorption was analyzed by a global fit involving four exponential functions, yielding time constants of $0.9 \mathrm{ps}, 1.4 \mathrm{ps}, 1.6 \mathrm{~ns}$, and $>5 \mathrm{~ns}$. Alternatively, a global target analysis assuming an $\mathrm{A} \rightarrow \mathrm{B} \rightarrow \mathrm{C} \rightarrow \mathrm{D} \rightarrow \mathrm{E}$ reaction scheme (with " $\mathrm{A}$ " the initially excited state and "E" the ground state) was performed, and this procedure yielded, as expected, ${ }^{76}$ the same time constants in addition to the species-associated difference absorption spectra (SADS) shown in Figure 6. The SADS for species D is compatible with the TAA ${ }^{+}-\mathbf{B}-\mathbf{R u}^{+}$photoproduct, and the SADS for species $\mathrm{C}$ is attributed to the ${ }^{3} \mathrm{MLCT}$ state of the $\mathrm{Ru}(\mathrm{bpy})_{3}{ }^{2+}$ unit of $\mathbf{T A A}-\mathbf{B}-\mathbf{R u ^ { 2 + }}{ }^{2+}$ Precise identification of species A and B is not possible, but the initial ultrafast processes are likely to involve internal conversion from the optically excited (ligand-centered) state to the ${ }^{1}$ MLCT, intersystem crossing to the ${ }^{3}$ MLCT state, and (vibrational and solvent) relaxation of the ${ }^{3}$ MLCT state. ${ }^{77}$

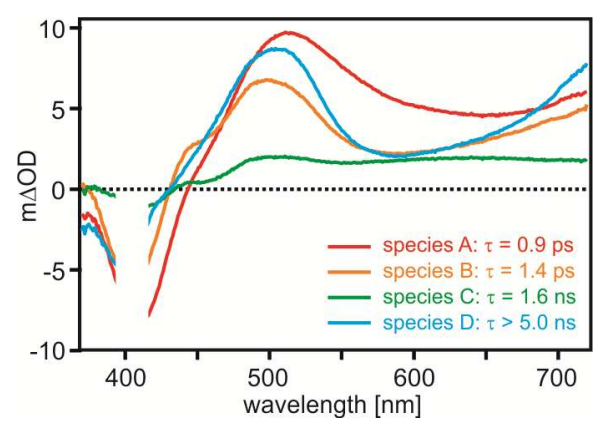

Figure 6. Species-associated difference spectra (SADS) extracted from the global target analysis of the fs/ps TA spectra measured for TAA-tmb-R $\mathbf{u}^{2+}$ in Figure 5. Analogous SADS for TAA-ph-Ru ${ }^{2+}$ are given in the Supporting Information (Figure S2). 
For the TAA-ph-Ru ${ }^{2+}$ dyad very similar transient absorption spectra are obtained (Figure S1), but the kinetic analysis yields time constants which are different from those obtained for TAA-tmb-Ru ${ }^{2+}$. Specifically, $0.9 \mathrm{ps}, 1.5 \mathrm{ps}, \sim 4 \mathrm{~ns}$, and $>5 \mathrm{~ns}$ are found; the respective SADS of an $\mathrm{A} \rightarrow \mathrm{B} \rightarrow \mathrm{C} \rightarrow \mathrm{D} \rightarrow$ E reaction sequence are shown in Figure S2. In analogy to TAA-tmb-Ru ${ }^{2+}$, species "C" is attributed to the ${ }^{3}$ MLCT state and species "D" is assigned to the $\mathbf{T A A}{ }^{+}-\mathbf{p h}-\mathbf{R} \mathbf{u}^{+}$photoproduct. Given the $0-1.5 \mathrm{~ns}$ time window of the experimental (fs/ps) setup, only an approximate value of $\sim 4$ ns can be estimated for the time constant for the electron transfer process $C \rightarrow D$.

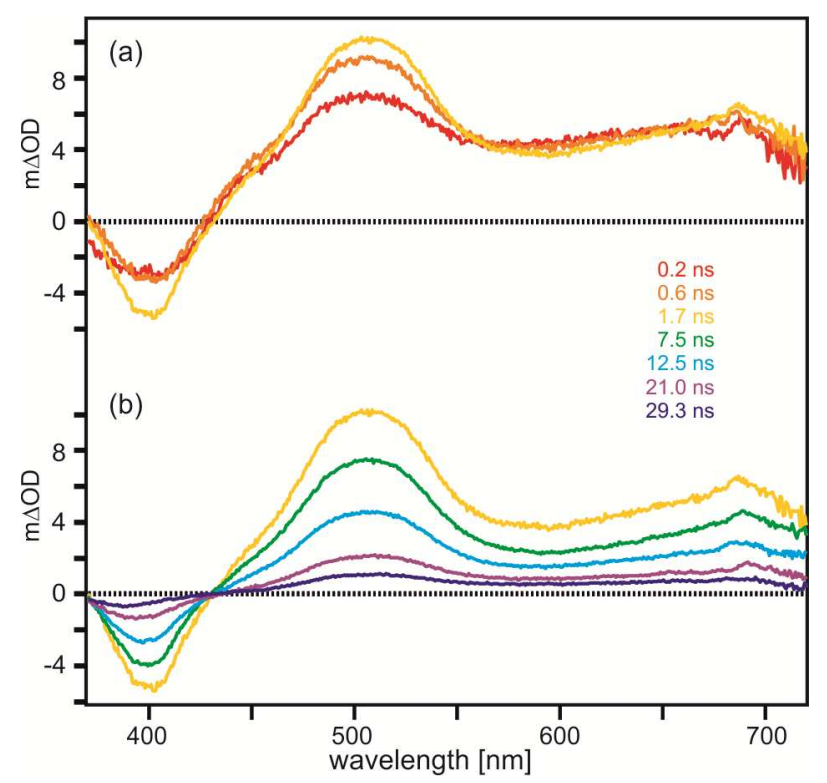

Figure 7. Transient absorption spectra measured at different time delays after excitation of TAA-tmb$\mathbf{R} \mathbf{u}^{2+}$ in de-aerated $\mathrm{CH}_{3} \mathrm{CN}$ at $355 \mathrm{~nm}$ using a sub-ns/ $\mu$ s TA setup. ${ }^{78}$ Analogous data for the TAA-ph$\mathbf{R} \mathbf{u}^{2+}$ dyad are reported in the Supporting Information (Figure S3).

Additional experiments which permit detection of transient absorption spectra beyond $1.5 \mathrm{~ns}$ were therefore performed on a different setup using excitation at $355 \mathrm{~nm} .^{78}$ These experiments allow more reliable determination of the rate constants for photoinduced electron transfer (process $\mathrm{C} \rightarrow \mathrm{D}$ ) and for thermal reverse electron transfer (process $\mathrm{D} \rightarrow \mathrm{E}$ ). Transient absorption spectra recorded with this (sub- 
$\mathrm{ns} / \mu \mathrm{s})$ setup at different time delays for the TAA-tmb- $\mathbf{R} \mathbf{u}^{2+}$ dyad in de-aerated $\mathrm{CH}_{3} \mathrm{CN}$ are shown in Figure 7. Expectedly, the same spectral features as detected above (Figure 5) are observed, but they can be followed over a significantly longer time range. On the nanosecond timescale one can identify three decay times, namely 1.5 ns, 10 ns and 560 ns. The respective SADS are shown in Figure 8. The time constant of $1.5 \mathrm{~ns}$ is attributed to intramolecular electron transfer from TAA to photoexcited Ru(bpy) ${ }_{3}{ }^{2+}$, and this value is in line with that extracted from the fs/ps studies (1.6 ns) reported above (Figure 5). The time constant of $10 \mathrm{~ns}$ is attributed to intramolecular reverse electron transfer from the reduced ruthenium photosensitizer to oxidized $\mathrm{TAA}^{+}$(process $\mathrm{D} \rightarrow \mathrm{E}$ ); to maintain consistency between Figures 5 and Figure 7, the respective species is labelled " $\mathrm{D}$ " in both cases. This value is more accurate than that extracted from the fs/ps studies in Figure 5; in the studies with higher temporal resolution reported above it was merely possible to determine a lower limit of $5 \mathrm{~ns}$ for thermal reverse electron transfer in the TAA-tmb-Ru ${ }^{2+}$ dyad. Finally, the time constant of $560 \mathrm{~ns}$ is attributed to an impurity which escaped detection in the analytical methods used to characterize TAA-tmb-R $\mathbf{u}^{2+}$ but which contributes (to a minor extent) to the transient absorption spectra in Figure 6. The respective SADS in Figure 8 is labelled with "X".

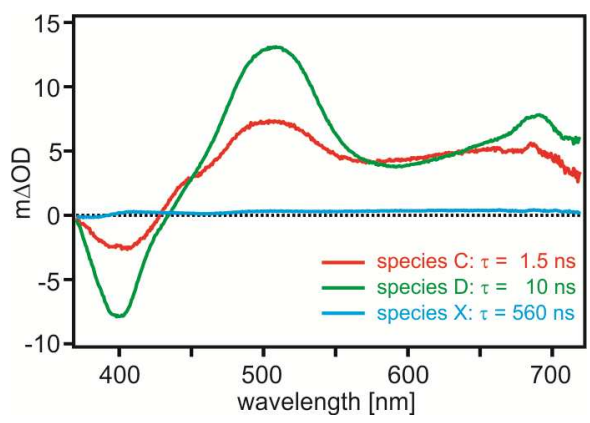

Figure 8. Species-associated difference spectra (SADS) extracted from the global target analysis of the

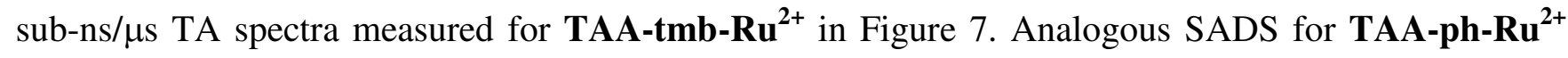
are given in the Supporting Information (Figure S4). 
Analogous experiments were performed with the TAA-ph- $\mathbf{R} \mathbf{u}^{2+}$ reference dyad in $\mathrm{CH}_{3} \mathrm{CN}$, and the respective transient absorption spectra are reported in Figure S3. From the SADS in Figure S4, three species-associated decay times can be extracted. In this case they are $6.8 \mathrm{~ns}, 10 \mathrm{~ns}$, and $490 \mathrm{~ns}$. In analogy to the TAA-tmb-Ru ${ }^{2+}$ dyad, they are attributed to the time constants for electron transfer from TAA to ${ }^{3}$ MLCT-excited $\mathrm{Ru}(\mathrm{bpy})_{3}{ }^{2+}$ (process $\mathrm{C} \rightarrow \mathrm{D}$ ), to thermal reverse electron transfer (process $\mathrm{D} \rightarrow$ E), and to a (minor) impurity, respectively. All relevant rate constants for intramolecular electron transfer are summarized in Table 2.

Table 2. Time constants for intramolecular electron transfer in de-aerated $\mathrm{CH}_{3} \mathrm{CN}$ at $20{ }^{\circ} \mathrm{C}$.

\begin{tabular}{|c|c|c|}
\hline & forward $^{a}$ & reverse $^{b}$ \\
\hline TAA-tmb-Ru ${ }^{2+}$ & $1.5 \mathrm{~ns}$ & $10 \mathrm{~ns}$ \\
\hline TAA-ph-Ru ${ }^{2+}$ & $6.8 \mathrm{~ns}$ & $10 \mathrm{~ns}$ \\
\hline
\end{tabular}

\footnotetext{
${ }^{a}$ Photoinduced electron transfer from TAA to ${ }^{3} \mathrm{MLCT}$-excited $\mathrm{Ru}(\mathrm{bpy})_{3}{ }^{2+} ;{ }^{b}$ Thermal electron transfer from $\mathrm{Ru}(\mathrm{bpy})_{3}{ }^{+}$to $\mathrm{TAA}^{+}$.
}

Physical origin of different rate constants for photoinduced electron transfer. In both dyads the time constants for photoinduced electron transfer $\left(2^{\text {nd }}\right.$ column in Table 2$)$ are significantly shorter than the time constant for thermal electron transfer in the reverse direction $\left(3^{\text {rd }}\right.$ column of Table 2$)$. At first first, this finding is surprising because the driving-force and reorganization energy analysis made above suggested that thermal reverse electron transfer occurs closer to the activationless regime than photoinduced (forward) electron transfer. However, in addition to the so-called nuclear factor whose magnitude is determined by the interplay between driving-force $\left(\Delta \mathrm{G}_{\mathrm{ET}}{ }^{0}, \Delta \mathrm{G}_{\mathrm{bET}}{ }^{0}\right)$ and reorganization energy $(\lambda)$, the so-called electronic factor governs the rate constants for electron transfer. ${ }^{73}$ As noted earlier, the electronic factor can be very different for photoinduced forward and thermal reverse electron transfer because different molecular orbitals are involved in the two processes. ${ }^{7,}{ }^{79} \mathrm{We}$ assume that it is primarily this effect which makes photoinduced electron transfer faster than thermal reverse electron 
transfer in our dyads.

The key finding from this study is that the equidistant intramolecular electron transfer from TAA to

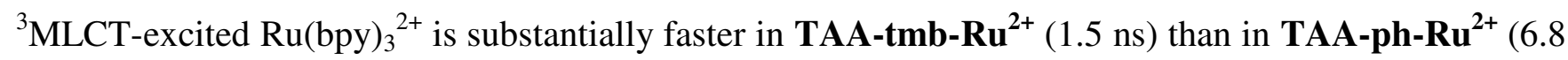
$\mathrm{ns})$. We attribute this difference to stronger electronic coupling $\left(\mathrm{H}_{\mathrm{DA}}\right)$ between the TAA and Ru(bpy $)_{3}{ }^{2+}$ units in the dyad with the tmb bridging unit. According to superexchange theory, ${ }^{80}$ the electronic coupling between a donor (D) and an acceptor (A) separated by $n$ identical bridging units (b) is given by equation $3.1,8,38$

$$
H_{D A}=\frac{h_{D b}}{\Delta \varepsilon} \cdot\left(\frac{h_{b b}}{\Delta \varepsilon}\right)^{n-1} \cdot h_{b A}
$$

In equation $3, h_{D b}, h_{b b}$, and $h_{b A}$ represent the electronic couplings between the donor and the adjacent bridging unit, between two neighboring bridging units, and between the last bridging unit and the acceptor, respectively. ${ }^{1,8}$ The parameter $\Delta \varepsilon$ is called tunneling energy gap and corresponds to the energy difference between the donor-acceptor system at the transition state configuration and the one-electron reduced or oxidized states of the bridge, depending on whether electron or hole transfer is considered (Scheme 4). ${ }^{7,8,38,81}$

Scheme 4. Illustration of the tunneling energy gap $(\Delta \varepsilon){ }^{a}$

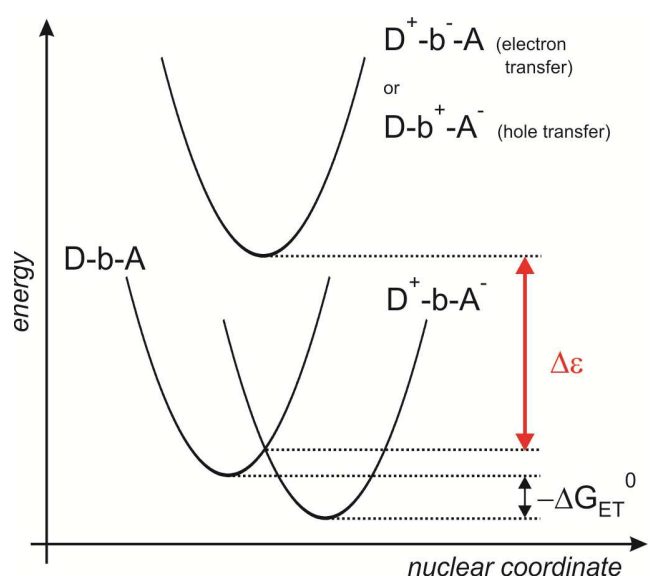


${ }^{a} \mathrm{D}$ stands for donor, $\mathrm{b}$ stands for bridge, and $\mathrm{A}$ stands for acceptor. $\Delta \mathrm{G}_{\mathrm{ET}}{ }^{0}$ is the reaction free energy associated with electron transfer from $\mathrm{D}$ to $\mathrm{A}$.

In practice, $\Delta \varepsilon$ is often approximated as the difference between the donor oxidation and bridge reduction potentials when considering electron transfer, or as the difference between the acceptor reduction and bridge oxidation potentials when dealing with hole transfer. ${ }^{3 \mathrm{a}, \mathrm{b}, 5 \mathrm{a}, 20}$ In our dyads $n=1$ (only single bridging units are present), and it seems plausible that the $h_{\mathrm{Db}}$ and $\mathrm{h}_{\mathrm{bA}}$ terms in equation 3 are very similar for tmb and ph bridging units. However, $\Delta \varepsilon$ is expected to be substantially different for tetramethoxybenzene and un-substituted phenylene, because the former can be oxidized significantly more easily due to its electron-donating substituents. The reduction of tmb and ph occurs at very negative potentials, and therefore it seems likely that a hole transfer rather than an electron transfer mechanism is operative in the dyads from Scheme 2. The oxidation potentials of tmb and ph are $0.42 \mathrm{~V}$ vs. $\mathrm{Fc}^{+} / \mathrm{Fc}$ and $2.10 \mathrm{~V}$ vs. $\mathrm{Fc}^{+} / \mathrm{Fc}$, respectively (Table 1). ${ }^{45,46,67}$ The acceptor reduction potentials are

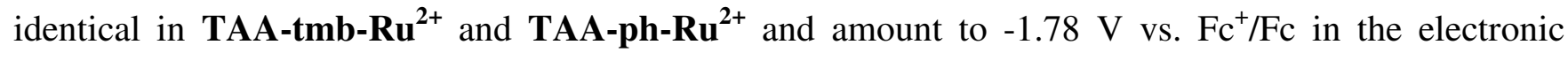
ground state (Table 1). In the ${ }^{3} \mathrm{MLCT}$ excited state, they are $0.34 \mathrm{~V}$ vs. $\mathrm{Fc}^{+} / \mathrm{Fc}$ because the ${ }^{3} \mathrm{MLCT}$ energy is $2.12 \mathrm{eV} .{ }^{63}$ Consequently, the estimated tunneling energy gaps are $\Delta \varepsilon=0.08 \mathrm{eV}$ for TAA-tmb$\mathbf{R} \mathbf{u}^{2+}$ and $\Delta \varepsilon=1.76 \mathrm{eV}$ for $\mathbf{T A A}-\mathbf{p h}-\mathbf{R} \mathbf{u}^{2+}$. This difference is substantial, and it can explain the difference in time constants for photoinduced electron transfer in the respective two dyads (1.5 vs. 6.8 ns, Table 2).

In the superexchange model for electron transfer, the one-electron reduced or oxidized states of the bridges are never actually populated but they are merely virtual states which define the height of the tunneling barrier associated with long-range electron transfer. ${ }^{38,82}$ However, in the TAA-tmb-Ru $^{2+}$ dyad the estimated $\Delta \varepsilon$ value is very low $(0.08 \mathrm{eV})$. Given the uncertainty associated with its approximation, the possibility of a hole hopping process in which oxidized tmb is formed as a reaction intermediate cannot be excluded a priori. However, the ultrafast time-resolved experiments reported 
above provide no evidence for the formation of tetramethoxybenzene cation with its characteristic absorption at $450 \mathrm{~nm} .{ }^{83} \mathrm{In}$ any case it seems plausible that the low oxidation potential of tmb compared to ph plays a key role for the kinetics of photoinduced electron transfer.

Curiously, the time constants for thermal reverse electron transfer from the reduced ruthenium complex to the oxidized triarylamine are identical in both dyads (10 ns, Table 2). Assuming a hole transfer mechanism is operative, one estimates $\Delta \varepsilon=0.19 \mathrm{eV}$ and $\Delta \varepsilon=1.87 \mathrm{eV}$ for the charge-shift from $\mathrm{TAA}^{+}$to tmb and ph, respectively, and this leads to the expectation of more rapid hole transfer in the tmb-bridged dyad. However, it is possible that the accelerating effect brought about by the lower $\Delta \varepsilon$ value in the tmb dyad is outbalanced by weaker electronic coupling $\left(\mathrm{h}_{\mathrm{bA}}\right)$ between tmb and TAA ${ }^{+}$with respect to ph and $\mathrm{TAA}^{+}$; the formation of triarylamine monocation is expected to be associated with geometrical changes which may include torsion along the C-C triple bond between tmb/ph and $\mathrm{TAA}^{+}$, and this effect could be more pronounced in the sterically more demanding tmb unit relative to the unsubstituted ph spacer. ${ }^{49,50,84}$

\section{SUMMARY AND CONCLUSIONS}

Alkoxy-substituents are frequently used to improve the solubility of rigid rod-like oligo- $p$-phenylene vinylene (OPV) and oligo-p-phenylene ethynylene (OPE) wires. ${ }^{11,13,36,85-98}$ Usually, the phenylene units of these oligomers or polymers are substituted with two alkoxy-groups in para-position to each other, because this leads to the desired solubility enhancement. We hypothesized that fourfold methoxysubstitution would lower the oxidation potential of the resulting molecular wire to the extent that significant rate enhancement for hole transfer can be achieved. This hypothesis was verified by the comparative study of the two dyads from Scheme 2 which showed that the tetramethoxybenzene spacer of TAA-tmb-Ru $\mathbf{u}^{2+}$ permits more rapid charge transfer by about a factor of 4.5 than the un-substituted phenylene spacer of TAA-ph-R $\mathbf{u}^{2+}$. Consequently, fourfold alkoxy-substitution might be generally 
beneficial in molecular wires, particularly in OPEs where the presence of more than two substituents on the phenylene units is less likely to have a detrimental effect on overall $\pi$-conjugation than in OPVs. In OPVs there might be some steric hindrance between alkoxy-groups and adjacent alkene $\mathrm{H}$ atoms, but at present we have no evidence that fourfold alkoxy-substitution on OPVs should not be possible.

\section{ACKNOWLEDGMENT}

This work was supported by the Swiss National Science Foundation through grant number 200021_146231/1.

\section{SUPPORTING INFORMATION PARAGRAPH}

Synthetic protocols and product characterization data, description of equipment and methods, details from X-ray diffraction analysis of ligand 21, additional transient absorption data. This material is available free of charge via the Internet at http://pubs.acs.org.

\section{REFERENCES}

(1) Gray, H. B.; Winkler, J. R. Long-Range Electron Transfer. Proc. Natl. Acad. Sci. U. S. A. 2005, $102,3534-3539$.

(2) Winkler, J. R.; Gray, H. B. Long-Range Electron Tunneling. J. Am. Chem. Soc. 2014, 136, 29302939.

(3) Weiss, E. A.; Ahrens, M. J.; Sinks, L. E.; Gusev, A. V.; Ratner, M. A.; Wasielewski, M. R. Making a Molecular Wire: Charge and Spin Transport Through para-Phenylene Oligomers. J. Am. Chem. Soc. 2004, 126, 5577-5584. 
(4) Cordes, M.; Kottgen, A.; Jasper, C.; Jacques, O.; Boudebous, H.; Giese, B. Influence of Amino Acid Side Chains on Long-Distance Electron Transfer in Peptides: Electron Hopping via "Stepping Stones". Angew. Chem. Int. Ed. 2008, 47, 3461-3463.

(5) Malak, R. A.; Gao, Z. N.; Wishart, J. F.; Isied, S. S. Long-Range Electron Transfer across Peptide Bridges: The Transition from Electron Superexchange to Hopping. J. Am. Chem. Soc. 2004, $126,13888-13889$.

(6) Berlin, Y. A.; Hutchison, G. R.; Rempala, P.; Ratner, M. A.; Michl, J. Charge Hopping in Molecular Wires as a Sequence of Electron-Transfer Reactions. J. Phys. Chem. A 2003, 107, 39703980.

(7) Albinsson, B.; Eng, M. P.; Pettersson, K.; Winters, M. U. Electron and Energy Transfer in Donor-Acceptor Systems with Conjugated Molecular Bridges. Phys. Chem. Chem. Phys. 2007, 9, 58475864.

(8) Wenger, O. S. How Donor-Bridge-Acceptor Energetics Influence Electron Tunneling Dynamics and Their Distance Dependences. Acc. Chem. Res. 2011, 44, 25-35.

(9) Edwards, P. P.; Gray, H. B.; Lodge, M. T. J.; Williams, R. J. P. Electron Transfer and Electronic Conduction through an Intervening Medium. Angew. Chem. Int. Ed. 2008, 47, 6758-6765.

(10) Atienza-Castellanos, C.; Wielopolski, M.; Guldi, D. M.; van der Pol, C.; Bryce, M. R.; Filippone, S.; Martín, N. Determination of the Attenuation Factor in Fluorene-Based Molecular Wires. Chem. Commun. 2007, 5164-5166.

(11) Fortage, J.; Goransson, E.; Blart, E.; Becker, H. C.; Hammarström, L.; Odobel, F. Strongly Coupled Zinc Phthalocyanine-Tin Porphyrin Dyad Performing Ultra-Fast Single Step Charge Separation over a 34 Angstrom Distance. Chem. Commun. 2007, 4629-4631. 
(12) Eng, M. P.; Albinsson, B. Non-Exponential Distance Dependence of Bridge-Mediated Electronic Coupling. Angew. Chem. Int. Ed. 2006, 45, 5626-5629.

(13) Giacalone, F.; Segura, J. L.; Martín, N.; Guldi, D. M. Exceptionally Small Attenuation Factors in Molecular Wires. J. Am. Chem. Soc. 2004, 126, 5340-5341.

(14) Harriman, A.; Ziessel, R. Making Photoactive Molecular-Scale Wires. Chem. Commun. 1996, 1707-1716.

(15) Soler, M.; McCusker, J. K. Distinguishing between Dexter and Rapid Sequential Electron Transfer in Covalently Linked Donor-Acceptor Assemblies. J. Am. Chem. Soc. 2008, 130, 4708-4724.

(16) Shih, C.; Museth, A. K.; Abrahamsson, M.; Blanco-Rodriguez, A. M.; Di Bilio, A. J.; Sudhamsu, J.; Crane, B. R.; Ronayne, K. L.; Towrie, M.; Vlček, A.; Richards, J. H.; Winkler, J. R.; Gray, H. B. Tryptophan-Accelerated Electron Flow through Proteins. Science 2008, 320, 1760-1762.

(17) Meylemans, H. A.; Hewitt, J. T.; Abdelhaq, M.; Vallett, P. J.; Damrauer, N. H. Exploiting Conformational Dynamics To Facilitate Formation and Trapping of Electron-Transfer Photoproducts in Metal Complexes. J. Am. Chem. Soc. 2010, 132, 11464-11466.

(18) Schlicke, B.; Belser, P.; De Cola, L.; Sabbioni, E.; Balzani, V. Photonic Wires of Nanometric Dimensions. Electronic Energy Transfer in Rigid Rodlike Ru(bpy $)_{3}{ }^{2+}-(\mathrm{ph})_{\mathrm{n}}-\mathrm{Os}(\mathrm{bpy})_{3}{ }^{2+}$ Compounds (ph=1,4-phenylene; n=3, 5, 7). J. Am. Chem. Soc. 1999, 121, 4207-4214.

(19) Montes, V. A.; Perez-Bolivar, C.; Agarwal, N.; Shinar, J.; Anzenbacher, P. Molecular-Wire Behavior of OLED Materials: Exciton Dynamics in Multichromophoric $\mathrm{Alq}_{3}$-Oligofluorene-Pt(II) Porphyrin Triads. J. Am. Chem. Soc. 2006, 128, 12436-12438.

(20) Montes, V. A.; Zyryanov, G. V.; Danilov, E.; Agarwal, N.; Palacios, M. A.; Anzenbacher, P. Ultrafast Energy Transfer in Oligofluorene-Aluminum Bis(8-hydroxyquinoline)acetylacetone 
Coordination Polymers. J. Am. Chem. Soc. 2009, 131, 1787-1795.

(21) Indelli, M. T.; Chiorboli, C.; Flamigni, L.; De Cola, L.; Scandola, F. Photoinduced Electron Transfer across Oligo-p-Phenylene Bridges. Distance and Conformational Effects in $\mathrm{Ru}(\mathrm{II})-\mathrm{Rh}(\mathrm{III})$ Dyads. Inorg. Chem. 2007, 46, 5630-5641.

(22) Sauvage, J.-P.; Collin, J.-P.; Chambron, J.-C.; Guillerez, S.; Coudret, C.; Balzani, V.; Barigelletti, F.; De Cola, L.; Flamigni, L. Ruthenium(II) and Osmium(II) Bis(Terpyridine) Complexes in Covalently-Linked Multicomponent Systems - Synthesis, Electrochemical Behavior, Absorption Spectra, and Photochemical and Photophysical Properties. Chem. Rev. 1994, 94, 993-1019.

(23) O'Hanlon, D. C.; Cohen, B. W.; Moravec, D. B.; Dallinger, R. F.; Hopkins, M. D. Electronic, Redox, and Photophysical Consequences of Metal-for-Carbon Substitution in Oligo-PhenyleneEthynylenes. J. Am. Chem. Soc. 2014, 136, 3127-3136.

(24) Simon, J. A.; Curry, S. L.; Schmehl, R. H.; Schatz, T. R.; Piotrowiak, P.; Jin, X. Q.; Thummel, R. P. Intramolecular Electronic Energy Transfer in Ruthenium(II) Diimine Donor Pyrene Acceptor Complexes Linked by a Single C-C Bond. J. Am. Chem. Soc. 1997, 119, 11012-11022.

(25) Baba, A. I.; Shaw, J. R.; Simon, J. A.; Thummel, R. P.; Schmehl, R. H. The Photophysical Behavior of $\mathrm{d}^{6}$ Complexes Having Nearly Isoenergetic MLCT and Ligand Localized Excited States. Coord. Chem. Rev. 1998, 171, 43-59.

(26) Schlundt, S.; Kuzmanich, G.; Spanig, F.; Rojas, G. D.; Kovacs, C.; Garcia-Garibay, M. A.; Guldi, D. M.; Hirsch, A. Dendritic Porphyrin-Fullerene Conjugates: Efficient Light-Harvesting and Charge-Transfer Events. Chem.-Eur. J. 2009, 15, 12223-12233.

(27) Siebert, R.; Akimov, D.; Schmitt, M.; Winter, A.; Schubert, U. S.; Dietzek, B.; Popp, J. Spectroscopic Investigation of the Ultrafast Photoinduced Dynamics in pi-Conjugated Terpyridines. 
ChemPhysChem 2009, 10, 910-919.

(28) Vail, S. A.; Krawczuk, P. J.; Guldi, D. M.; Palkar, A.; Echegoyen, L.; Tome, J. P. C.; Fazio, M. A.; Schuster, D. I. Energy and Electron Transfer in Polyacetylene-Linked Zinc-Porphyrin-[60]Fullerene Molecular Wires. Chem. Eur. J. 2005, 11, 3375-3388.

(29) Melomedov, J.; Ochsmann, J. R.; Meister, M.; Laquai, F.; Heinze, K. Tuning Reductive and Oxidative Photoinduced Electron Transfer in Amide-Linked Anthraquinone-Porphyrin-Ferrocene Architectures. Eur. J. Inorg. Chem. 2014, 2014, 1984-2001.

(30) Van Wallendael, S.; Rillema, D. P. Photoinduced Intramolecular Energy-Transfer from One Metal Center to the Other in a Mixed-Metal Ruthenium-Rhenium Complex. Coord. Chem. Rev. 1991, $111,297-318$.

(31) Bäuerle, P.; Segelbacher, U.; Gaudl, K. U.; Huttenlocher, D.; Mehring, M. Didodecylsexithiophene a Model-Compound for the Formation and Characterization of Charge-Carriers in Conjugated Chains. Angew. Chem. Int. Ed. 1993, 32, 76-78.

(32) He, J.; Chen, F.; Liddell, P. A.; Andreasson, J.; Straight, S. D.; Gust, D.; Moore, T. A.; Moore, A. L.; Li, J.; Sankey, O. F.; Lindsay, S. M. Switching of a Photochromic Molecule on Gold Electrodes: Single-Molecule Measurements. Nanotechnology 2005, 16, 695-702.

(33) Liddell, P. A.; Kodis, G.; Moore, A. L.; Moore, T. A.; Gust, D. Photonic Switching of Photoinduced Electron Transfer in a Dithienylethene-Porphyrin-Fullerene Triad Molecule. J. Am. Chem. Soc. 2002, 124, 7668-7669.

(34) Zhou, G.; Baumgarten, M.; Müllen, K. Arylamine-Substituted Oligo(Ladder-Type Pentaphenylene)s: Electronic Communication Between Bridged Redox Centers. J. Am. Chem. Soc. 2007, 129, 12211-12221. 
(35) Weiss, E. A.; Tauber, M. J.; Kelley, R. F.; Ahrens, M. J.; Ratner, M. A.; Wasielewski, M. R. Conformationally Gated Switching Between Superexchange and Hopping Within Oligo-p-PhenyleneBased Molecular Wires. J. Am. Chem. Soc. 2005, 127, 11842-11850.

(36) Tour, J. M. Conjugated Macromolecules of Precise Length and Constitution. Organic Synthesis for the Construction of Nanoarchitectures. Chem. Rev. 1996, 96, 537-553.

(37) Walther, M. E.; Wenger, O. S. Tuning the Rates of Long-Range Charge Transfer across Phenylene Wires. ChemPhysChem 2009, 10, 1203-1206.

(38) Natali, M.; Campagna, S.; Scandola, F. Photoinduced Electron Transfer Across Molecular Bridges: Electron- and Hole-Transfer Superexchange Pathways. Chem. Soc. Rev. 2014, 43, 4005-4018.

(39) Eng, M. P.; Albinsson, B. The Dependence of the Electronic Coupling on Energy Gap and Bridge Conformation Towards Prediction of the Distance Dependence of Electron Transfer Reactions. Chem. Phys. 2009, 357, 132-139.

(40) Miller, S. E.; Lukas, A. S.; Marsh, E.; Bushard, P.; Wasielewski, M. R. Photoinduced Charge Separation Involving an Unusual Double Electron Transfer Mechanism in a Donor-Bridge-Acceptor Molecule. J. Am. Chem. Soc. 2000, 122, 7802-7810.

(41) Lambert, C.; Nöll, G.; Schelter, J. Bridge-Mediated Hopping or Superexchange ElectronTransfer Processes in Bis(Triarylamine) Systems. Nat. Mater. 2002, 1, 69-73.

(42) Hanss, D.; Walther, M. E.; Wenger, O. S. Accelerated Hole Transfer Across a Molecular Double Barrier. Chem. Commun. 2010, 46, 7034-7036.

(43) Kilså, K.; Kajanus, J.; Macpherson, A. N.; Mårtensson, J.; Albinsson, B. Bridge-Dependent Electron Transfer in Porphyrin-Based Donor-Bridge-Acceptor Systems. J. Am. Chem. Soc. 2001, 123, 3069-3080. 
(44) Nelsen, S. F. Electron Transfer Reactions Within Sigma- and Pi-Bridged Dinitrogen-Centered Intervalence Radical Cations. Adv. Phys. Organ. Chem. 2006, 41, 183-215.

(45) Luo, P.; Feinberg, A. M.; Guirado, G.; Farid, S.; Dinnocenzo, J. P. Accurate Oxidation Potentials of 40 Benzene and Biphenyl Derivatives with Heteroatom Substituents. J. Org. Chem. 2014, 79, 9297-9304.

(46) Zweig, A.; Hodgson, W. G.; Jura, W. H. Oxidation of Methoxybenzenes. J. Am. Chem. Soc. 1964, $86,4124-\&$.

(47) Gonzalez, M. T.; Zhao, X. T.; Manrique, D. Z.; Miguel, D.; Leary, E.; Gulcur, M.; Batsanov, A. S.; Rubio-Bollinger, G.; Lambert, C. J.; Bryce, M. R.; Agrait, N. Structural versus Electrical Functionalization of Oligo(phenylene ethynylene) Diamine Molecular Junctions. J. Phys. Chem. C 2014, 118, 21655-21662.

(48) Walther, M. E.; Wenger, O. S. Hole Tunneling and Hopping in a Ru(bpy) ${ }^{2+}$-Phenothiazine Dyad with a Bridge Derived from oligo-p-Phenylene. Inorg. Chem. 2011, 50, 10901-10907.

(49) Benniston, A. C.; Harriman, A. Charge on the Move: How Electron-Transfer Dynamics Depend on Molecular Conformation. Chem. Soc. Rev. 2006, 35, 169-179.

(50) Lörtscher, E.; Elbing, M.; Tschudy, M.; von Hänisch, C.; Weber, H. B.; Mayor, M.; Riel, H. Charge Transport through Molecular Rods with Reduced pi-Conjugation. ChemPhysChem 2008, 9, $2252-2258$.

(51) Hanss, D.; Wenger, O. S. Conformational Effects on Long-Range Electron Transfer: Comparison of Oligo-p-Phenylene and Oligo-p-Xylene Bridges. Eur. J. Inorg. Chem. 2009, 3778-3790.

(52) Viault, G.; Grée, D.; Das, S.; Yadav, J. S.; Grée, R. Synthesis of a Focused Chemical Library Based on Derivatives of Embelin, a Natural Product with Proapoptotic and Anticancer Properties. Eur. 
J. Org. Chem. 2011, 1233-1241.

(53) Staab, H. A.; Weiser, J.; Futscher, M.; Voit, G.; Ruckemann, A.; Anders, C. Porphyrin-Quinone Cyclophanes with Gradually Varied Acceptor Strength - Syntheses and Characterizations. Chem. Ber. 1992, 125, 2285-2301.

(54) Poigny, S.; Guyot, M.; Samadi, M. Total Synthesis of Maesanin and Analogues. Tetrahedron 1998, 54, 14791-14802.

(55) Shu, W. F.; Guan, C. W.; Guo, W. H.; Wang, C. Y.; Shen, Y. J. Conjugated Poly(Aryleneethynylenesiloles) and Their Application in Detecting Explosives. J. Mater. Chem. 2012, $22,3075-3081$

(56) Fang, Y. Q.; Hanan, G. S. Rapid and Efficient Synthesis of Functionalized Bipyridines. Synlett 2003, 852-854.

(57) Hankache, J.; Wenger, O. S. Microsecond Charge Recombination in a Linear Triarylamine$\mathrm{Ru}(\mathrm{bpy})_{3}{ }^{2+}$-Anthraquinone Triad. Chem. Commun. 2011, 47, 10145-10147.

(58) Hensel, V.; Lutzow, K.; Jacob, J.; Gessler, K.; Saenger, W.; Schlüter, A. D. Repetitive Construction of Macrocyclic Oligophenylenes. Angew. Chem. Int. Ed. 1997, 36, 2654-2656.

(59) Hensel, V.; Schlüter, A. D. A Biphenyl Construction Kit for Modular Chemistry. Liebigs Ann. 1997, 303-309.

(60) Hanss, D.; Wenger, O. S. Tunneling Barrier Effects on Photoinduced Charge Transfer through Covalent Rigid Rod-Like Bridges. Inorg. Chem. 2009, 48, 671-680.

(61) Lambert, C.; Nöll, G.; Schmälzlin, E.; Meerholz, K.; Bräuchle, C. Synthesis, (Bon)Linear Optical and Redox Properties of a Donor-Substituted Truxenone Derivative. Chem. Eur. J. 1998, 4, 2129-2135. 
(62) Bonn, A. G.; Neuburger, M.; Wenger, O. S. Photoinduced Electron Transfer in Rhenium(I)Oligotriarylamine Molecules. Inorg. Chem. 2014, 53, 11075-11085.

(63) Vlček, A. A.; Dodsworth, E. S.; Pietro, W. J.; Lever, A. B. P. Excited-State Redox Potentials of Ruthenium Diimine Complexes - Correlations with Ground-State Redox Potentials and Ligand Parameters. Inorg. Chem. 1995, 34, 1906-1913.

(64) Juris, A.; Balzani, V.; Barigelletti, F.; Campagna, S.; Belser, P.; Von Zelewsky, A. Ru(II) Polypyridine Complexes - Photophysics, Photochemistry, Electrochemistry, and Chemi-Luminescence. Coord. Chem. Rev. 1988, 84, 85-277.

(65) Hankache, J.; Niemi, M.; Lemmetyinen, H.; Wenger, O. S. Photoinduced Electron Transfer in Linear Triarylamine-Photosensitizer-Anthraquinone Triads with Ruthenium(II), Osmium(II), and Iridium(III). Inorg. Chem. 2012, 51, 6333-6344.

(66) Sreenath, K.; Thomas, T. G.; Gopidas, K. R. Cu(II) Mediated Generation and Spectroscopic Study of the Tris(4-anisyl)amine Radical Cation and Dication. Unusually Shielded Chemical Shifts in the Dication. Org. Lett. 2011, 13, 1134-1137.

(67) Merkel, P. B.; Luo, P.; Dinnocenzo, J. P.; Farid, S. Accurate Oxidation Potentials of Benzene and Biphenyl Derivatives via Electron-Transfer Equilibria and Transient Kinetics. J. Org. Chem. 2009, $74,5163-5173$.

(68) Pavlishchuk, V. V.; Addison, A. W. Conversion Constants for Redox Potentials Measured Versus Different Reference Electrodes in Acetonitrile Solutions at 25 Degrees C. Inorg. Chim. Acta 2000, 298, 97-102.

(69) Geiss, B.; Lambert, C. A Small Cationic Donor-Acceptor Iridium Complex with a Long-Lived Charge-Separated State. Chem. Commun. 2009, 1670-1672. 
(70) Lambert, C.; Nöll, G. The Class II/III Transition in Triarylamine Redox Systems. J. Am. Chem. Soc. 1999, 121, 8434-8442.

(71) Weller, A. Photoinduced Electron-Transfer in Solution - Exciplex and Radical Ion-Pair Formation Free Enthalpies and Their Solvent Dependence. Z. Phys. Chem. 1982, 133, 93-98.

(72) Roundhill, D. M., Photochemistry and Photophysics of Metal Complexes. Plenum Press: New York, 1994.

(73) Marcus, R. A.; Sutin, N. Electron Transfers In Chemistry And Biology. Biochim. Biophys. Acta 1985, $811,265-322$.

(74) Barbara, P. F.; Meyer, T. J.; Ratner, M. A. Contemporary Issues in Electron Transfer Research. J. Phys. Chem. 1996, 100, 13148-13168.

(75) Banerji, N.; Duvanel, G.; Perez-Velasco, A.; Maity, S.; Sakai, N.; Matile, S.; Vauthey, E. Excited-State Dynamics of Hybrid Multichromophoric Systems: Toward an Excitation Wavelength Control of the Charge Separation Pathways. J. Phys. Chem. A 2009, 113, 8202-8212.

(76) van Stokkum, I. H. M.; Larsen, D. S.; van Grondelle, R. Global and Target Analysis of TimeResolved Spectra. Biochim. Biophys. Acta 2004, 1657, 82-104.

(77) Sun, Q. C.; Mosquera-Vazquez, S.; Daku, L. M. L.; Guénée, L.; Goodwin, H. A.; Vauthey, E.; Hausert, A. Experimental Evidence of Ultrafast Quenching of the ${ }^{3}$ MLCT Luminescence in Ruthenium(II) Tris-bipyridyl Complexes via a ${ }^{3}$ dd State. J. Am. Chem. Soc. 2013, 135, 13660-13663.

(78) Lang, B.; Mosquera-Vazquez, S.; Lovy, D.; Sherin, P.; Markovic, V.; Vauthey, E. Broadband Ultraviolet-Visible Transient Absorption Spectroscopy in the Nanosecond to Microsecond Time Domain with Sub-Nanosecond Time Resolution. Rev. Sci. Instrum. 2013, 84.

(79) Yonemoto, E. H.; Riley, R. L.; Kim, Y. I.; Atherton, S. J.; Schmehl, R. H.; Mallouk, T. E. 
Photoinduced Electron-Transfer in Covalently Linked Ruthenium Tris(Bipyridyl) Viologen Molecules Observation of Back Electron-Transfer in the Marcus Inverted Region. J. Am. Chem. Soc. 1992, 114, 8081-8087.

(80) McConnell, H. M. Intramolecular Charge Transfer In Aromatic Free Radicals. J. Chem. Phys. 1961, 35, 508-515.

(81) Tong, G. S. M.; Kurnikov, I. V.; Beratan, D. N. Tunneling Energy Effects on GC Oxidation in DNA. J. Phys. Chem. B 2002, 106, 2381-2392.

(82) Pettersson, K.; Wiberg, J.; Ljungdahl, T.; Mårtensson, J.; Albinsson, B. Interplay Between Barrier Width and Height in Electron Tunneling: Photoinduced Electron Transfer in Porphyrin-Based Donor-Bridge-Acceptor Systems. J. Phys. Chem. A 2006, 110, 319-326.

(83) Sato, H.; Guengerich, F. P. Oxidation of 1,2,4,5-Tetramethoxybenzene to a Cation Radical by Cytochrome P450. J. Am. Chem. Soc. 2000, 122, 8099-8100.

(84) Benniston, A. C.; Harriman, A.; Li, P.; Patel, P. V.; Sams, C. A. Electron Exchange in Conformationally Restricted Donor-Spacer-Acceptor Dyads: Angle Dependence and Involvement of Upper-Lying Excited States. Chem. Eur. J. 2008, 14, 1710-1717.

(85) Lloveras, V.; Vidal-Gancedo, J.; Figueira-Duarte, T. M.; Nierengarten, J. F.; Novoa, J. J.; Mota, F.; Ventosa, N.; Rovira, C.; Veciana, J. Tunneling versus Hopping in Mixed-Valence Oligo-pphenylenevinylene Polychlorinated Bis(triphenylmethyl) Radical Anions. J. Am. Chem. Soc. 2011, 133, 5818-5833.

(86) Ziener, U.; Godt, A. Synthesis and Characterization of Monodisperse Oligo(phenyleneethynylene)s. J. Org. Chem. 1997, 62, 6137-6143.

(87) Davis, W. B.; Svec, W. A.; Ratner, M. A.; Wasielewski, M. R. Molecular-Wire Behaviour in p- 
Phenylenevinylene Oligomers. Nature 1998, 396, 60-63.

(88) Smalley, J. F.; Sachs, S. B.; Chidsey, C. E. D.; Dudek, S. P.; Sikes, H. D.; Creager, S. E.; Yu, C. J.; Feldberg, S. W.; Newton, M. D. Interfacial Electron-Transfer Kinetics of Ferrocene through Oligophenyleneethynylene Bridges Attached to Gold Electrodes as Constituents of Self-Assembled Monolayers: Observation of a Nonmonotonic Distance Dependence. J. Am. Chem. Soc. 2004, 126, 14620-14630.

(89) Pettersson, K.; Kyrychenko, A.; Ronnow, E.; Ljungdahl, T.; Martensson, J.; Albinsson, B. Singlet Energy Transfer in Porphyrin-Based Donor-Bridge-Acceptor Systems: Interaction between Bridge Length and Bridge Energy. J. Phys. Chem. A 2006, 110, 310-318.

(90) Eng, M. P.; Ljungdahl, T.; Martensson, J.; Albinsson, B. Triplet Excitation Energy Transfer in Porphyrin-Based Donor-Bridge-Acceptor Systems with Conjugated Bridges of Varying Length: An Experimental and DFT Study. J. Phys. Chem. B 2006, 110, 6483-6491.

(91) Myahkostupov, M.; Piotrowiak, P.; Wang, D.; Galoppini, E. Ru(II)-Bpy Complexes Bound to Nanocrystalline $\mathrm{TiO}_{2}$ Films through Phenyleneethynylene (OPE) Linkers: Effect of the Linkers Length on Electron Injection Rates. J. Phys. Chem. C 2007, 111, 2827-2829.

(92) Clifford, J. N.; Gu, T.; Nierengarten, J. F.; Armaroli, N. Photoinduced Energy and Electron Transfer in Fullerene-Oligophenyleneethynylene Systems: Dependence on the Substituents of the Oligomer Unit. Photochem. Photobiol. Sci. 2006, 5, 1165-1172.

(93) de la Torre, G.; Giacalone, F.; Segura, J. L.; Martín, N.; Guldi, D. M. Electronic Communication Through pi-Conjugated Wires in Covalently Linked Porphyrin/C-60 Ensembles. Chem. Eur. J. 2005, $11,1267-1280$.

(94) Davis, W. B.; Ratner, M. A.; Wasielewski, M. R. Conformational Gating of Long Distance Electron Transfer Through Wire-Like Bridges in Donor-Bridge-Acceptor Molecules. J. Am. Chem. Soc. 
2001, 123, 7877-7886.

(95) Beckers, E. H. A.; van Hal, P. A.; Schenning, A.; El-ghayoury, A.; Peeters, E.; Rispens, M. T.; Hummelen, J. C.; Meijer, E. W.; Janssen, R. A. J. Singlet-Energy Transfer in Quadruple HydrogenBonded Pligo(p-Phenylenevinylene)-Fullerene Dyads. J. Mater. Chem. 2002, 12, 2054-2060.

(96) Huber, R.; González, M. T.; Wu, S.; Langer, M.; Grunder, S.; Horhoiu, V.; Mayor, M.; Bryce, M. R.; Wang, C. S.; Jitchati, R.; Schönenberger, C.; Calame, M. Electrical Conductance of Conjugated Oligorners at the Single Molecule Level. J. Am. Chem. Soc. 2008, 130, 1080-1084.

(97) Duvanel, G.; Grilj, J.; Vauthey, E. Ultrafast Long-Distance Excitation Energy Transport in Donor-Bridge-Acceptor Systems. J. Phys. Chem. A 2013, 117, 918-928.

(98) Linton, K. E.; Fox, M. A.; Palsson, L. O.; Bryce, M. R. Oligo(p-Phenyleneethynylene) (OPE) Molecular Wires: Synthesis and Length Dependence of Photoinduced Charge Transfer in OPEs with Triarylamine and Diaryloxadiazole End Groups. Chem.-Eur. J. 2015, 21, 3997-4007.

\section{SYNOPSIS TOC}

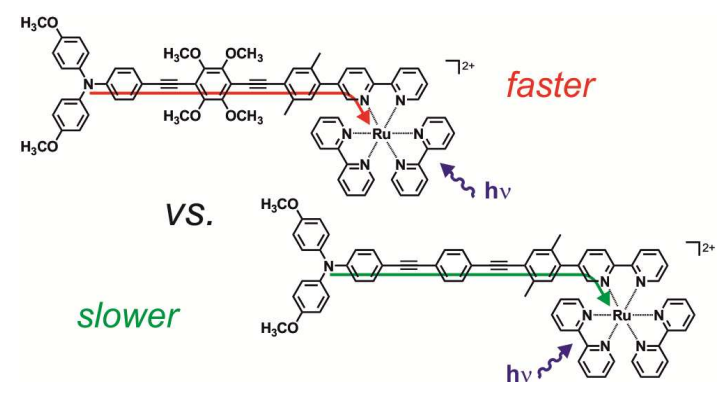

Photoinduced hole transfer across a tetramethoxybenzene spacer occurs more rapidly than across an unsubstituted phenylene spacer in triarylamine $-\mathrm{Ru}\left(2,2^{\prime} \text { '-bipyridine }\right)_{3}{ }^{2+}$ dyads because methoxysubstitution lowers the oxidation potential of the molecular bridge between the donor and the acceptor. 